\title{
A Learning Pathway to an Integrated Approach Involving Natural, Applied and Social Science, Humanities and Arts to Face Climate Change
}

\author{
Stefano Alessandri
}

\begin{abstract}
The main sources of information about climate change cited in this article are characterized by a close to unanimous agreement about their contents not only within the international scientific community but also within the community of the nations whose political representatives have to approve them together with scientists. These sources are accessible both by scientists who have a background in natural and applied science, and by policy makers-professionals whose expertise is in fields other than natural and applied sciences. These sources are a good starting point for everyone wishing to be reliably informed about the reported subjects. The main issues related to the changing climate system are summarized with comments that underline the known feedback, their consequences, and the growing discussions about them inside the international scientific community. Also discussed are scientists' efforts to properly and effectively inform policy makers and to help to design feasible mitigation strategies that make sense, could be accepted by the public, and could achieve results. The main sources of anthropogenic greenhouse gases emission are briefly described and the importance of the transition to an economy based on renewable energies and recycling is underlined. Two cases are included to show how the humanities, social sciences, and the arts could proactively work with natural and applied sciences, local communities, and society at large to imagine, plan, and build effective solutions. This article aims to be a primer on communication among different disciplines that have different competencies and roles and which could be an effective way to enlist citizen participation and commitment to build a sustainable future.
\end{abstract}

Keywords: climate change; environmental awareness; interdisciplinary studies; participation; sustainability

\section{Introduction}

This article, which reviews current research on climate change, is aimed at non-scientists, scholars, and students, as well as scientists whose fields are not directly involved in the study of climate change. This overview is meant to contribute to increasing environmental knowledge and awareness in as comprehensible a way as possible, with an eye toward filling the current gap between science and society, science and humanities, and science and the arts.
The integration of these worlds of knowledge seems critically low; in the present period, however, it should be considered essential in the face of the environmental, demographic, social, and economical crises in the near future. Given the huge wealth of information, the overall consensus suggests a needed strategy for climate change mitigation. The strong connection between the fields of natural and applied sciences and social sciences, humanities, and the arts opens a dialogue for discussing the problems and issues across disciplines. Crossing the borders of one's field of knowledge and daring to approach the contents of another can lead to the creation of unexpected and sustainable ways to creatively work toward improving our uncertain future.

Reliable sources have been selected herein to offer the most useful tools to acquire and sift through the relevant information about the main known elements that comprise the big picture of our warming climate system as a whole. These sources can be used to enable critical reflection 
and autonomous judgment, increasing readers' capability for evaluating a broad range of information. The point of view is neither specialized nor generic; rather, it proposes an integrated approach to a complexity of subjects, none of which can be disregarded or undervalued in a field in which new issues are discovered every year.

\section{The Climate Is Changing and the Atmosphere, the Land Surface, and the Oceans Are Warming}

The main actors promoting studies, discussions, and agreements about climate can be considered the United Nations (UN), ${ }^{1}$ the most internationally represented intergovernmental organization, and some of its affiliates like the World Meteorological Organization (WMO). ${ }^{2}$ The WMO is a specialized agency that publishes and distributes the conclusions of the most authoritative studies on the state and behavior of the Earth's atmosphere and its interaction with land, oceans, weather, and climate. The United Nations Environment Programme (UNEP), ${ }^{3}$ also an agency of United Nations, coordinates the environmental activities of the organization.

In 1988, UNEP and WMO established the Intergovernmental Panel on Climate Change (IPCC), ${ }^{4}$ whose mission is to provide the world with a clear scientific view on the current state of knowledge regarding climate change and its potential environmental and socioeconomic impacts, and to provide rigorous and balanced scientific information to decision makers. It must be emphasized that "governments participate in the review process and the plenary sessions, where main decisions about the IPCC work programme are taken and reports are accepted, adopted and approved." The IPCC guarantees a very thorough assessment and a strong commitment to effective communication, especially between scientists and decision makers. Each one of the three organizations (WMO, UNEP, and IPCC) provides a webpage where its publications can be downloaded for free. ${ }^{6-8}$

The WMO Statement on the State of the Global Climate ${ }^{9}$ is of special interest because it is very concise and readable. It is published annually, with updated information on climate summarized and presented in graphical and textual format, including clear commentary. The WMO annual reports are also a good starting point for foundational information about the subject. The 2017 report, ${ }^{10}$ for example, explains the following:

- The global temperature is increasing.

- This increase is consistent with other changes in the climate system.

- Carbon dioxide concentration in the atmosphere is increasing.

- The influence of human activities on the climate system is becoming more and more evident.

The IPCC reports are designed to be understood by both scientists and policy makers. The report content must be approved by all the members of the panel, and the organization's writing and review process is extremely complex and detailed. ${ }^{11}$ In general, the reports are lengthy, but include summaries that allow a quick review of the main points, conclusions, and scientific findings, as well as a detailed study and discussion of the supporting research and its results. IPCC recently published its
Fifth Assessment Report ${ }^{12}$ in four volumes, one for each of the three Working Groups of the IPCC, plus a Synthesis Report. ${ }^{13}$

The IPCC Working Group I (WG I) works on the physical scientific aspects of climate and climate change. ${ }^{14}$ The WG II takes a global ${ }^{15}$ and a regional ${ }^{16}$ point of view to work on the vulnerability and needed adaptation of socioeconomic and natural systems to climate change and its consequences. The focus of WG III is on the options for mitigating climate change by limiting or preventing greenhouse gas emissions and by removing them from the atmosphere. ${ }^{17}$ The Synthesis Report synthesizes and integrates materials contained within other reports and contains both a detailed report and a Summary for Policymakers, which concisely highlights the conclusions of each subject.

The IPCC Fifth Assessment Report as a whole ${ }^{13-17}$ offers an extremely concise, readable, and operational summary of a detailed report that assesses the most advanced research and its results. This report states that:

- Global warming, since the 1950s, is unequivocal and unprecedented over decades to millennia and is characterized by the fact that almost the entire globe has experienced and is experiencing surface warming.

- Anthropogenic greenhouse gas emissions have increased since the pre-industrial erafrom 2000 to 2010 emissions were the highest in history.

- The atmospheric concentrations of greenhouse gases are unprecedented in the last 800,000 years and are extremely likely to have been the dominant cause of the observed warming. 
- Between 1880 and 2012, the globally-averaged combined land and ocean surface temperature shows a warming trend of $0.85^{\circ} \mathrm{C}$ per decade.

- The ocean temperatures are of special significance because they are strongly associated with the whole Earth's energy imbalance. Ocean warming accounts for more than 90 percent of the energy accumulated by the Earth's climate system between 1971 and 2010 (only about 1 percent is stored in the atmosphere). The upper 75 meters of the ocean has warmed by $0.11^{\circ} \mathrm{C}$ per decade over the same period.

\section{Greenhouse Effect and Greenhouse Gases}

A greenhouse is a heat trap that allows the temperature inside the greenhouse to be greater than that of the external environment:

- Visible light enters the greenhouse and a fraction of it is absorbed by the internal environment, causing a rise in temperature.

- A fraction of the absorbed energy is emitted again as thermal infrared radiation.

- Infrared radiation cannot escape through the covering material and contributes to the further warming of the internal environment by radiative transfer.

- The same covering material also prevents convective cooling.

- Convective cooling can be controlled opening windows and/or doors, or removing the covering material.

The Earth's climate system is powered by the sun. Approximately 50 percent of the solar radiation reach- ing the Earth is visible light. About half of this energy is absorbed by the Earth's surface; approximately 30 percent is reflected to space by aerosols, clouds, and the Earth's surface; and about 20 percent is absorbed in the atmosphere. The Earth's surface emits an outgoing energy flux, mainly as infrared radiation, which is partially absorbed by clouds and by components of the atmosphere that are defined as greenhouse gases (GHGs) and consist of: water vapor $\left(\mathrm{H}_{2} \mathrm{O}\right)$, carbon dioxide $\left(\mathrm{CO}_{2}\right)$, methane $\left(\mathrm{CH}_{4}\right)$, nitrous oxide $\left(\mathrm{N}_{2} \mathrm{O}\right)$, and chlorofluorocarbons. In turn, these gases emit infrared radiation in all directions, adding heat to the lower layers of the atmosphere and to the Earth's surface. This is called greenhouse effect. ${ }^{18}$

In 2011 the recorded atmospheric concentrations of carbon dioxide, methane, and nitrous oxide were all shown to have increased since the pre-industrial era (reference year 1750 ) by about 40 percent, 150 percent, and 20 percent, respectively. Their concentrations in 2011 were greater than the highest concentrations recorded in ice cores over the past 800,000 years. ${ }^{19}$ In 2016, globally-averaged surface concentration of carbon dioxide, methane, and nitrous oxide reached 403.3 parts per million (ppm), 1,853 parts per billion (ppb), and $328.9 \mathrm{ppb}$, respectively, corresponding to 145 percent, 257 percent, and 122 percent of preindustrial levels. ${ }^{20}$ Radiative Forcing (RF) is the imbalance of energy flowing in and out of the Earth's atmosphere, and is measured in watt per square metre $\left(\mathrm{W} / \mathrm{m}^{2}\right)$. It is a useful measure for comparing the drivers of global mean surface temperature affecting the Earth's energy flux. Relative to 1750 , industrial era RF for carbon dioxide alone $\mathrm{e}^{10}$ is $1.82 \mathrm{~W} / \mathrm{m}^{2}$. The evolution of the total anthropogenic
$\mathrm{RF}$ from the pre-industrial era to the present shows a nearly continuous increase, with a much greater rate of increase since 1960, corresponding to the increase in anthropogenic greenhouse gas concentrations, with carbon dioxide acting as the largest single contributor.

The Global Monitoring Division of the Earth System Research Laboratory of the National Oceanic and Atmospheric Administration (NOAA) publishes online, updated each spring, values of RF and of a related index called Annual Greenhouse Gas Index (AGGI). ${ }^{21}$ AGGI is defined as the ratio between the total direct RF due to long-lived greenhouse gases for any year and the RF of 1990 (the baseline year for the Kyoto Protocol).

- For 2016 the AGGI was 1.40, an increase in total direct RF of 40 percent since 1990, with nearly 54 percent due to $\mathrm{CO}_{2}$.

- From 1990 to 2015, radiative forcing by long-lived greenhouse gases increased by 37 percent, with $\mathrm{CO}_{2}$ accounting for about 80 percent of this increase. For 2017, the AGGI was 1.41 , with nearly 56 percent due to $\mathrm{CO}_{2}$.

To evaluate and compare the impact of the different substances on our climate system, metrics other than RF and AGGI are also widely used: Global Warming Potential (GWP) and Global Temperature change Potential (GTP). Global Warming Potential (GWP) takes into account not only the Radiative Forcing of a certain substance, but also its lifetime in the atmosphere, and can be considered a measure of its radiative efficiency with reference to a particular time horizon. GWP gives values relative to those for the reference gas $\mathrm{CO}_{2}$. Global Temperature change 
Potential (GTP) also considers the climate response to a certain substance. It is based on the change in Global Medium Surface Temperature at a chosen point in time, relative to that caused by the reference gas $\mathrm{CO}_{2}$.

According to the IPCC, the values shown in Table 1 can be used as an updated reference. ${ }^{13}$ Among other things, they show that methane, over 100 years, has Global Warming Potential that is 28 times the GWP of $\mathrm{CO}_{2}$ and a Global Temperature change Potential that is four times the GTP of $\mathrm{CO}_{2}$.

Greenhouse gases warm the troposphere (the region of the atmosphere from the Earth's surface to an altitude of about $9 \mathrm{~km}$ at high latitudes and to $16 \mathrm{~km}$ in the tropics), and cool the stratosphere (the region of the atmosphere above the troposphere, to an altitude of about $50 \mathrm{~km}$ ). Ozone $\left(\mathrm{O}_{3}\right)$ is a more complex actor in this process. In the tropospherewhere it is created both naturally and by photochemical reactions of oxygen with methane, carbon monoxide, volatile organics, and nitrogen oxides-ozone acts as a greenhouse gas. It also has a detrimental impact on vegetation physiology and therefore on $\mathrm{CO}_{2}$ uptake of all plant life. In the stratosphere, where ozone is the product of interaction between solar ultraviolet radiation and molecular oxygen $\left(\mathrm{O}_{2}\right)$, it plays a prominent role in warming the stratosphere itself. $^{22}$

Ozone concentrations are highest in the so-called ozone layer, which extends from about 12 to $40 \mathrm{~km}$ above the Earth's surface. The ozone layer has been depleted by human emissions of chlorine and bromine compounds, and this depletion decreases the stratosphere warming, especially in the polar regions (ozone hole) and is expected to cause cooler Antarctic surface temperatures.

\section{Glaciers, Snow Cover, Sea Ice, Ice Caps, and Ice Sheets}

Over the past three decades, Arctic summer sea ice retreat has been unprecedented, and sea surface temperatures have been anomalously high, measured against the norms of at least the last 1,450 years. The extent of Northern Hemisphere snow cover has decreased and permafrost temperatures have increased in most regions. In parts of the Russian European North, a considerable reduction in both the thickness and areal extent of the permafrost has been observed. Following a very substantial Arctic region warming, the areal extent of Arctic sea ice de-
Table 1. Global Warming Potential (GWP) and Global Temperature Change Potential (GTP) of the More Relevant Greenhouse Gases*

\begin{tabular}{|c|c|c|c|c|c|}
\hline \multirow[b]{3}{*}{$\begin{array}{l}\text { Greenhouse } \\
\text { Gas (GHG) }\end{array}$} & \multirow[b]{3}{*}{$\begin{array}{l}\text { Lifetime } \\
\text { years }\end{array}$} & \multirow{2}{*}{\multicolumn{2}{|c|}{$\begin{array}{c}\begin{array}{c}\text { Global Warming } \\
\text { Potential (GWP) }\end{array} \\
\text { Cumulative forcing over }\end{array}$}} & \multirow{2}{*}{\multicolumn{2}{|c|}{$\begin{array}{c}\begin{array}{c}\text { Global Temperature } \\
\text { Change Potential (GTP) }\end{array} \\
\text { Temperature change after }\end{array}$}} \\
\hline & & & & & \\
\hline & & 20 years & 100 years & 20 years & 100 years \\
\hline $\mathrm{CO}_{2}$ & & 1 & 1 & 1 & 1 \\
\hline $\mathrm{CH}_{4}$ & 12.4 & 84 & 28 & 67 & 4 \\
\hline $\mathrm{N}_{2} \mathrm{O}$ & 121.0 & 264 & 265 & 277 & 234 \\
\hline HFC & 1.5 & 506 & 138 & 174 & 19 \\
\hline
\end{tabular}

*(GHGs): Reported values are relative to $\mathrm{CO}_{2}$. creased at a rate of 3.5 to 4.1 percent per decade. The annual period of surface melt on Arctic perennial sea ice lengthened by 5.7 days per decade, and in the region between the East Siberian Sea and the western Beaufort Sea, the duration of ice-free conditions increased by nearly three months. $^{23}$ The Arctic ice retreat could accelerate even faster because further reductions in seasonal ice cover will result in larger waves, which in turn provide a mechanism for breaking up the sea ice. ${ }^{24}$

On the other hand, the annual areal Antarctic sea ice has increased at a rate of between 1.2 and 1.8 percent per decade, but with strong regional differences in the rate and in the length of the ice-free season. The Antarctic ice sheet has been losing ice over the last two decades, mainly from the northern Antarctic Peninsula and the Amundsen Sea sector of West Antarctica, due to the acceleration of outlet glaciers. ${ }^{23}$ This acceleration has been widely observed where glaciers are melting and is thought to depend on a mechanism of lubrication that was first observed on Alpine glaciers. ${ }^{25}$ When it cools, liquid water becomes more dense until reaching $3.98^{\circ} \mathrm{C}$. Between $3.98^{\circ} \mathrm{C}$ and $0^{\circ} \mathrm{C}$, the density decreases with decreasing temperature. Therefore a convective movement can start in a melting pond, carrying the denser and warmer (near $3.98^{\circ} \mathrm{C}$ ) water to where it can act to melt the ice on the bottom where it cools (near $0^{\circ} \mathrm{C}$ ), becomes less dense, and together with the water from the just-melted ice, is carried upward by the convective flow. A moulin can form that can reach the bedrock and lubricate the glacial flow.

According to Zwally et al. ${ }^{26}$ this kind of lubrication can accelerate ice flow during the periods of summer melting 
and decelerate it after the melting ceases, with interannual variations in the ice acceleration correlated to variations in the intensity of the surface melting.

Rignot and Kanagaratnam ${ }^{27}$ using satellite radar interferometry observations of Greenland observed expanding glacier acceleration that in the east doubled the loss of ice sheet mass between 1996 and 2005, indicating that the contribution of Greenland to sea-level rise could continue to increase more than expected given the growing number of accelerating glaciers. According to models by Shannon et al., ${ }^{28}$ however, the lubrication modifies the flow and form of the ice sheet, but should not substantially affect net mass loss because increase to sealevel rise from basal lubrication by all their models is no more than 5 percent of the contribution from surface mass alone.

Overall, there is general agreement about the following:

- The Greenland ice sheet has lost ice during the last two decades and the loss of mass has accelerated since 1992 at an average rate that has increased from $34 \mathrm{Gt}$ (billions tons) per year over the period between 1992 and 2001, to 215 Gt per year over the period between 2002 and 2011, corresponding to a contribution to sea-level increase that passed from $0.09 \mathrm{~mm}$ to $0.59 \mathrm{~mm}$ per year. ${ }^{23}$

- Almost all glaciers worldwide are persistently shrinking, with measured changes in glacier length, area, volume, and mass.

- Satellite data about snow cover show decreases through the year between 1967 and 2012 especially in June (53\%) and stations usually report decreases especially in spring.

\section{Permafrost and Circumpolar Lakes}

A special attention must be paid to permafrost thawing

Ground that remains at or below $0^{\circ} \mathrm{C}$ for at least two consecutive years is called permafrost and can be located beneath the land surface (terrestrial permafrost) or beneath the seafloor (subsea permafrost). Permafrost is characterized by high quantities of organic matter and by the methane and carbon dioxide that are trapped in it as metastable gas hydrates. ${ }^{29}$

Terrestrial permafrost temperatures have increased in most regions since the early 1980s (up to $3^{\circ} \mathrm{C}$ in parts of Northern Alaska and up to $2^{\circ} \mathrm{C}$ in parts of the Russian European North, where a considerable reduction in permafrost thickness and areal extent has been observed, with surface subsidence occurring at many locations). These increases are attributable to increased air temperature and to changes in the timing and thickness of snow cover. By the end of the 21st century, the area of permafrost near the surface (upper $3.5 \mathrm{~m}$ ) is projected to decrease by more than 35 percent. ${ }^{19}$

The release of $\mathrm{CO}_{2}$ or $\mathrm{CH}_{4}$ to the atmosphere from thawing permafrost thus far in the 21st century is assessed to be more than 50 Gigatons of carbon (GtC). Reservoirs of carbon in hydrates and permafrost are very large and could potentially act as very powerful feedbacks, enhancing the global greenhouse effect. ${ }^{19,30}$ In addition, in a warming climate, permafrost thawing may induce further decomposition of carbon accumulated in frozen soils, leading to a further increase of atmospheric carbon dioxide and methane concentrations. ${ }^{19}$
Methane release is expected also from warming circumpolar lakes ${ }^{31,32}$ and from subsea permafrost through the undersaturated state of the ocean, the long ventilation time of the ocean, and the slow propagation of warming through the seafloor, could slow methane release. On the other hand the high instability of subsea deposits is a source of concern. However, while ocean warming enhances the instability of these deposits, the sea-level rise due to changes in ocean mass increases the water pressure at the ocean floor enhancing their stability.

In summary, anthropogenic warming will very likely lead to enhanced $\mathrm{CH}_{4}$ emissions from both terrestrial and subsea permafrost if all the information available is taken into account. $^{19}$

\section{Warming of the Oceans and Sea Level Rise}

Average ocean temperature has changed over the past 40 years and in the period between 1901 and 2010 Global Mean Sea Level (GMSL) rose by $0.19 \mathrm{~m}$. The rate of sea level rise since the mid-19th century has been higher than the mean rate over the previous two millennia. ${ }^{13}$ Increases in the volume of ocean water are primarily due to the thermal expansion of the ocean water and the transfer to the ocean of water previously stored on land, particularly from glaciers and ice sheets. Water impoundment in reservoirs and groundwater depletion (and its subsequent runoff to the ocean) also affect sea level.

During the 20th century, the mean rate of sea-level rise was $1.7 \mathrm{~mm} / \mathrm{yr}$ between 1901 and 2010, a rate that nearly doubled, to $3.2 \mathrm{~mm} / \mathrm{yr}$, between 1993 and 2010. By 2300, GMSL rise above the pre-industrial level 
could be around $1 \mathrm{~m}$, assuming $\mathrm{CO}_{2}$ concentrations are below $500 \mathrm{ppm}^{33}$

By the end of the 21st century, about 70 percent of the coastlines worldwide may experience sea-level change within 20 percent of the global mean. Sea level could rise in more than 95 percent of the ocean area, but it has not been and will not be uniform. For example, since 1993, the regional rates for the Western Pacific Ocean were up to three times larger than the global mean, while those for much of the Eastern Pacific Ocean were near zero or negative. ${ }^{33}$ Change in sea level relative to the land (relative sea level) can be significantly different from the global mean sea level change because of variations in the redistribution of water in the ocean and of ice on the land, both of which are related to vertical movement of the land and variations in the Earth's gravitational field. ${ }^{33}$ According to Kopp et al. ${ }^{34}$ regional sea level will change due to dynamical ocean circulation changes, variations in the heat content of the ocean, mass redistribution in the entire Earth system, and changes in atmospheric pressure.

Ocean dynamical change is caused by variations in wind and buoyancy forcing, and associated changes in the circulation and redistribution of heat and freshwater. Ice sheet mass loss, glacier mass loss, and changes in terrestrial hydrology cause water mass redistribution among the cryosphere, the land, and the oceans, giving rise to regional changes in the solid Earth ${ }^{35}$ and the gravity field. In some coastal locations, changes in the hydrological cycle, ground subsidence associated with anthropogenic activity, tectonic processes, and coastal processes can dominate the change in sea surface height relative to the land.
Regional variations in sea level could reach up to 30 percent above the global mean value in the Southern Ocean and around North America, between 10 and 20 percent in equatorial regions, and up to 50 percent below the global mean in the Arctic region and some regions near Antarctica. ${ }^{34}$ According to Sweet et al., ${ }^{36}$ if recent observational and modeling results about rapid ice melt in Greenland and Antarctica are considered, Global Mean Sea Level rise for year 2100 could be in the range of 2.0 to $2.7 \mathrm{~m}$. This is consistent with recent observations of Antarctic icesheet instability.

\section{Tropospheric Water Vapor and Precipitation Change}

The saturation vapor pressure of air increases with temperature. Therefore it is expected that the amount of water vapor in air will increase with a warming climate. The observed global change in tropospheric water vapor over the past 40 years is about 3.5 percent, which is consistent with the observed temperature change of about $0.5^{\circ} \mathrm{C}$ and with the observed oceanic surface salinity. The observed oceanic surface salinity is highly correlated with the difference between evaporation and precipitation and since the 1950s, regions of high salinity (and high evaporation) have increased in salinity while regions of low salinity (and high rainfall) have become fresher. A pattern of evaporation minus precipitation can be inferred and is consistent with the observed increased water vapor content of the warmer air and indicates an increase in global mean precipitation. ${ }^{22,37}$

The number of heavy precipitation events has generally increased even more than global mean precipitation. In North America and Europe, either the frequency or the intensity of heavy precipitation has increased, with seasonal and regional variations, and trends toward heavier precipitation events have been observed in central North America. Since the 1970s, the frequency and intensity of storms in the North Atlantic have increased.

Mean global-scale precipitation is predicted to gradually increase with warming, but the increase in intensity of extreme precipitation events will be even greater. Changes in average precipitation will not be uniform. High latitude regions will experience greater amounts of precipitation while many mid-latitude and subtropical arid and semi-arid regions will experience less. These changes imply increasing aridity in already dry areas, and possible expansion of deserts. Model projections show rainfall becoming more intense and precipitation events occurring less frequently. Therefore more floods are expected and also more drought due to longer dry periods between rain events. ${ }^{22,37}$

Currently, several regions are experiencing severe drought crises. Between 1951 and 2010, the number of cold days and nights has decreased and the number of warm days and nights has increased on the global scale; the length and frequency of heat waves have increased in large parts of Europe, Asia, and Australia. The frequency and intensity of droughts have increased in the Mediterranean and West Africa and have decreased in central North America and northwest Australia. ${ }^{22,37}$

According to Trenberth, Fasullo, and Shepherd, ${ }^{38}$ changes in the atmospheric circulation related to climate change can be considered small when compared to natural variability. However, since the climate is changing, the environment in which all weather 
events occur is different, and this makes all events different (extreme) because they occur in a different, more vulnerable environment and have a different, stronger impact.

\section{Acidification of the Oceans and Biodiversity Loss}

The increase of the global atmospheric concentration of carbon dioxide since the pre-industrial era is related to the 26 percent increase in the acidity of the oceans, corresponding to a $\mathrm{pH}$ variation from 8.2 to 8.1 . By 2100 the average surface ocean $\mathrm{pH}$ could be lower than it has been for more than 50 million years. ${ }^{39,40}$

The solubility of carbon dioxide is higher than the solubility of oxygen and nitrogen, but the dissolution of $\mathrm{CO}_{2}$ in the oceans is a very slow process compared to that of current GHG emissions in the atmosphere. Therefore absorption of $\mathrm{CO}_{2}$ in the oceans cannot be thought as a remedy to its increasing atmospheric concentration. On the contrary, it is a source of major concern, one that has been analyzed, discussed, and summarized in two reports and then updated by the IPCC in the Fifth Assessment Report:

1. Ocean Acidification Due to Increasing Atmospheric Carbon Dioxide, ${ }^{41}$ written by a workgroup of European scientists organized by the Royal Society, whose council endorsed its findings; and

2. Impacts of Ocean Acidification on Coral Reefs and Other Marine Calcifiers: A Guide for Future Research, ${ }^{42}$ from a workshop sponsored by the National Science Foundation, the National Oceanic and Atmospheric Administration, and the U.S. Geological Survey.

Both publications are available free online.
The following considerations are partly inspired by these two documents.

1. Carbon dioxide is different from the other main atmospheric gases because it reacts with water, starting a series of reactions in which the following chemical species and the related equilibriums are involved: atmospheric carbon dioxide $\left(\mathrm{CO}_{2}(\mathrm{~g})\right)$ and carbon dioxide in water solution $\left(\mathrm{CO}_{2}(\mathrm{aq})\right)$; carbonic acid $\left(\mathrm{H}_{2} \mathrm{CO}_{3}(\mathrm{aq})\right)$ as the first product of the reaction between water and $\mathrm{CO}_{2}(\mathrm{aq})$; the hydrogen carbonate anion $\left(\mathrm{HCO}_{3}{ }^{-}(\mathrm{aq})\right)$, which is the product of the first dissociation of carbonic acid, and the carbonate anion $\left(\mathrm{CO}_{3}{ }^{2-}(\mathrm{aq})\right)$, which is the product of its second dissociation.

2. Under current ocean conditions, bicarbonate is the most abundant form of $\mathrm{CO}_{2}$ dissolved in seawater, followed by carbonate and then by aqueous $\mathrm{CO}_{2}(\mathrm{aq})$. There is approximately an order of magnitude difference in abundance between each of the inorganic carbon compounds, with variation dependent on seawater temperature, salinity, and pressure. All three are important for the biological processes of marine organisms, which include acidity buffering, calcification (providing structures such as $\mathrm{CaCO}_{3}$ shells), and photosynthesis by marine algae (mostly phytoplankton).

3. The increase of atmospheric $\mathrm{CO}_{2}$ concentration results in an increase of seawater acidity $\left(\mathrm{H}^{+}\right.$concentration, though buffered, slightly increases) and an increase in total inorganic carbon content in the sea environment, but it is accompanied by a decrease of availability of $\mathrm{CO}_{3}{ }^{2-}$ (aq) and an increase in the dissolution of solid carbonate $\mathrm{CaCO}_{3}(\mathrm{~s})$. In these conditions the biological systems-for instance coral-experience rising difficulty in building their skeletons and experience the erosion of their calcium carbonate structures.

4. Acidification not only reduces the carbonate saturation level of the seawater, making calcification harder and weakening already-formed structures, but also can modify the equilibriums, the concentrations, and the biological availability of chemical elements that are fundamental for metabolism such as magnesium, iron, and manganese.

5. The ocean's capacity to absorb atmospheric $\mathrm{CO}_{2}$ is inhibited by water acidification, making it more difficult to stabilize atmospheric $\mathrm{CO}_{2}$ concentrations.

6. Ocean acidification is expected to have major negative impacts on corals and other marine organisms whose success is largely controlled by carbonate chemistry. Many calcifying species are located at the bottom or in the middle of global ocean food webs.

Therefore their loss will alter predator-prey relationships and the effects will be transmitted throughout the ecosystem, with the likely disruptions of large components of the marine food web and a loss or change in biodiversity. ${ }^{41,42}$ 
7. Global marine species redistribution and marine biodiversity reduction in sensitive regions will challenge the sustained productivity of fisheries and other ecosystem services, exacerbating the damage of overfishing and undermining food security.

8. Marine ecosystems are at risk from climate change and often show limited adaptive capacity. They can be damaged not only by ocean acidification and rising water temperature per se, but also by decreased oxygen solubility and, in coastal environments, by sea level rise. ${ }^{13} \mathrm{~A}$ warmer climate may increase hypoxia in sensitive areas due to the combined effects of decreased oxygen solubility and increased respiration rates, which would magnify the negative effects of eutrophication. ${ }^{43}$

9. If eutrophic regions are not considered, $\mathrm{CO}_{2}$ storage by photosynthesis is not expected to increase. Plankton growth could remain roughly unchanged because it is limited mostly by nutrients and light, not by the availability of inorganic carbon. On land, vegetation absorbs $\mathrm{CO}_{2}$ by photosynthesis, but this process is critically dependent on factors such as water and nutrient availability and less on $\mathrm{CO}_{2}$ concentration. ${ }^{39}$

\section{A Summary about Positive Feedbacks in Climate Change}

The feedbacks in climate change are extensively discussed through the whole Fifth IPCC Report and are treated in depth in Climate Change 2013: The Physical Science Basis, ${ }^{14}$ which explains that tropospheric water vapor, lapse rate (the decrease of temperature with altitude), albedo, and cloud feedbacks are the main determinants $^{19}$ of equilibrium climate sensitivity (ECS). All of these feedbacks are assessed to be positive, though cloud feedbacks show a large uncertainty.

Tropospheric concentration of water vapor is increasing and there is evidence of a positive feedback from the combination of water vapor as a greenhouse gas and lapse rate changes.

The albedo decreases as highly reflective ice and snow surfaces melt, exposing the darker and more absorbing surfaces below, either on the ocean or on the land. In the Arctic, as surface albedo decreases, air temperatures increase, and the ocean can absorb more heat and contribute to further sea ice melting. Furthermore, ice sheets and glaciers show enhanced calving at their margins because the ice flow is accelerated by lubrication. Arctic ice retreat could accelerate because further reductions in seasonal ice cover of the ice sea will result in larger waves, which in turn contribute to breaking up sea ice.

The loss of carbon (as carbon dioxide and methane) from frozen soils and methane hydrates constitutes a further positive radiative feedback. A positive feedback is also caused by the decreasing carbon uptake by the ocean because of lower $\mathrm{CO}_{2}$ solubility in a more acidic and warmer sea water. Climate models also indicate that less carbon is absorbed by land as the atmosphere warms because on land, longer seasonal growth periods in temperate and higher latitudes are coupled with faster respiration of soil carbon.

The elucidation of these feedbacks by the international scientific community and the growing awareness of their role in accelerating the observable and predicted consequences of climate change, both in the short term and long term, could explain the trend that can be observed in the graph shown in Figure 1. The steep rise in the number of scientific publications per year during the second half of the first decade

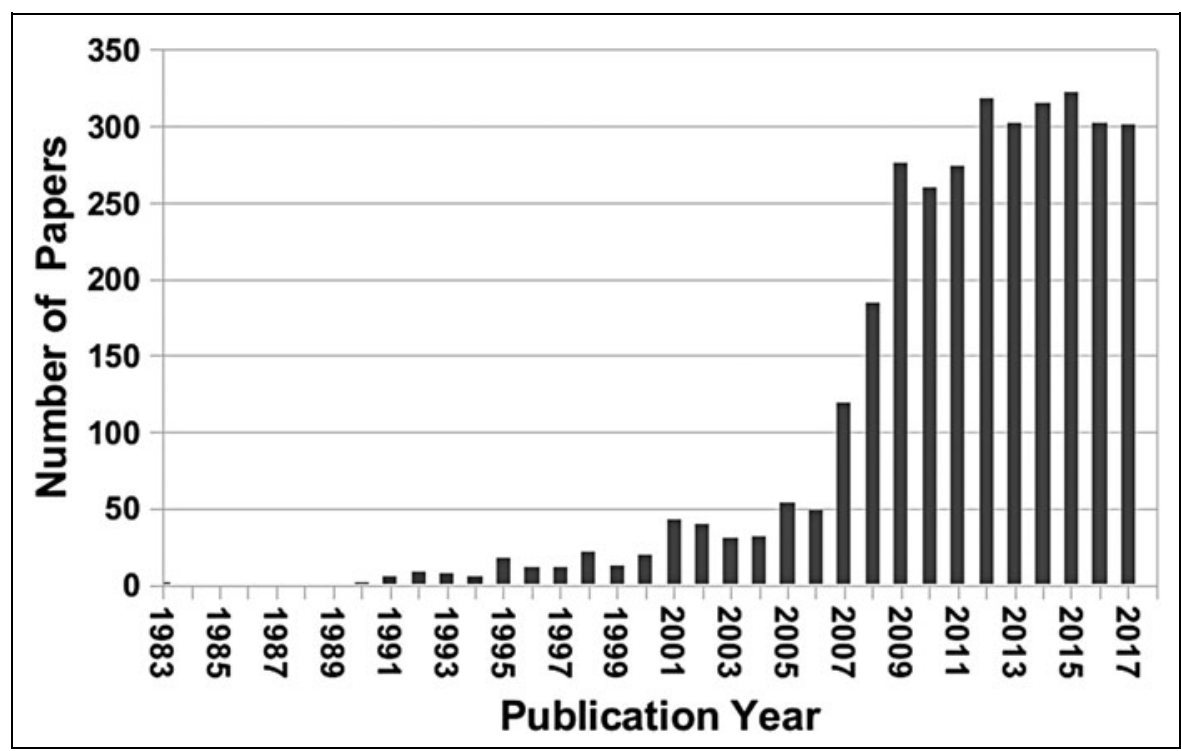

Figure 1. Results of search on Google Scholar using keywords "climate change" and "faster than predicted" or "faster than prediction" or "faster than expected" (excluding patents and citations) 
of the 2000s may indicate a corresponding growing awareness of the pressing need to mitigate climate change if the accelerating feedbacks are considered, and may be related to the commitment that can be perceived reading the Paris Agreement and the corresponding adoption document. $^{44}$

\section{A Short Discussion about the Production Sectors, Their Greenhouse Gases Emissions, and Some Critical Issues for the Acceptance of a New Economy}

\section{Energy Supply Systems}

The $\mathrm{CO}_{2}$ emitted to the atmosphere from the burning of fossil fuels is the main culprit of climate change. If anthropogenic emissions of greenhouse gases were stopped now, their associated impacts would continue for centuries, but the risks of abrupt or irreversible changes depend on the magnitude of the warming, which can be affected by societal choices, both now and in the immediate future. $^{13,45-47}$ The energy supply sector (including the energy extraction, conversion, storage, transmission, and distribution processes that deliver final energy to the end-use sectors) is the largest contributor to global greenhouse gas emissions. ${ }^{17}$ The stabilization of GHG concentrations at low levels requires a fundamental transformation of the energy supply system.

\section{Renewable Energy}

The aggregated global technical potential for Renewable Energy (RE) as a whole is significantly higher than global energy demands. Solar has the largest potential, but there is also great potential for many other forms of $\mathrm{RE}$. The regional distribution of solar is also an important consideration. Fischedick et al. ${ }^{48}$ report that there is no obvious single dominant RE technology likely to be deployed at a global level, but bioenergy, wind, and solar may experience the largest incremental growth. The mix of RE technologies suited to a specific location depend on local conditions, with hydropower and geothermal playing a significant role in certain countries. Though the regional distribution of each source varies, the technical potential of RE as a whole is at least 2.6 times as large as the 2007 total primary energy demand in all regions of the world and could definitely contribute to the mitigation of climate change. $^{48}$

A growing number of Renewable Energy technologies (wind, hydro, and solar power) can be deployed at significant scale. While they are already economically competitive, they are mainly deployed within larger, centralized energy networks even though they could be decentralized and deployed at the point of use.

Decentralized RE systems can meet rural and small-community energy needs in areas that are not served by an electric grid. Technologies in these areas include various modern advanced and traditional biomass options as well as small hydropower, photovoltaic, and wind. RE technology policies have been successful in driving the recent growth of RE. Furthermore, renewable energy plants are often associated with co-benefits: reduction of air pollution; local employment opportunities; fewer severe accidents compared to some other energy supply technologies, especially if small decentralized plants are considered. It must be taken into account that medium- and large-scale hydro plants not only produce energy but they also ensure effective water man- agement and soil protection, and can become tourism destinations by allowing recreational use.

\section{Nuclear Energy}

Nuclear energy is a mature, lowGHG emission energy source and could make an increasing contribution to low-carbon energy supply. However, a variety of barriers and risks exist that make this solution questionable, including operational risks and the associated safety concerns, uranium mining risks, financial and regulatory risks, unresolved waste management issues, nuclear weapon proliferation concerns, and adverse public opinion. Furthermore though nuclear power does not directly emit GHG, significant lifecycle emissions occur through plant construction, operation, uranium mining and milling, and plant decommissioning. According to Sovacool, ${ }^{49}$ Life Cycle Analysis (LCA) puts nuclear in an intermediate position: It scores much better than all fossil fuel technologies, but worse than all renewable technologies.

New fuel cycles and reactor technologies that can address some of these critical issues are under development. Small modular reactors (SMRs) with additional passive safety features could be especially promising. ${ }^{50}$ The size of these reactors is typically less than $300 \mathrm{MWe}$, much smaller than the $1000 \mathrm{MWe}$ (or larger) typical of current light-water reactors (LWR). Recently designed SMRs with low power density, large heat capacity, and heat removal through natural means have the potential for enhanced safety ${ }^{50}$ and should be characterized by economies of manufacturing from modular construction techniques, shorter construction periods, incremental power capacity additions, and potential for improved financing. ${ }^{50}$ 
Several SMR designs are in development. Light-water SMRs rely on substantial experience with current LWRs and utilize existing fuel-cycle infrastructure. Gas-cooled SMRs operate at higher temperatures and have the potential for increased electricity generation efficiency relative to LWRs and industrial applications as a source of high-temperature process heat. ${ }^{51}$ Small nuclear fusion reactors are of special interest and are giving promising results in the research lab. ${ }^{52}$ The fusion process could avoid the risks associated with waste management issues, nuclear weapon proliferation, radiological pollution, and the limited availability of fission fuels.

Current market and technology conditions limit extraction of conventional uranium resources to concentrations above $100 \mathrm{ppm}$, necessitating the development of improved and less expensive extraction technologies. According to the International Atomic Energy Agency (IAEA), present uranium resources are sufficient to fuel existing energy demand for more than 130 years, and if all conventional known sources of uranium are considered, for more than 250 years. ${ }^{17}$ Reprocessing of spent fuel and recycling of uranium and plutonium by fast-breeder reactor technology could theoretically increase uranium utilization 50-fold or even more with corresponding reductions in high-level waste (HLW) generation and disposal requirements, ${ }^{51}$ but the current technology is burdened by relevant safety issues.

\section{Carbon Dioxide Capture and Storage}

Carbon dioxide capture and storage (CCS) technologies are problematic because of barriers to their largescale deployment. There are concerns about the operational safety and long-term integrity of $\mathrm{CO}_{2}$ storage, and risks related to the transport and to the required upscaling of the involved infrastructure. Furthermore, the $\mathrm{CO}_{2}$ pressure build-up within a geologic formation could induce seismicity, and $\mathrm{CO}_{2}$ leakage can significantly impact groundwater chemistry and the quality of drinking water, ${ }^{53}$ resulting in acidification, eutrophication, and toxicity due to pollution induced by the mobilization of heavy metals. ${ }^{54}$

According to IPCC, ${ }^{17}$ Carbon Dioxide Removal (CDR) could play an important role in many mitigation scenarios, but bioenergy with carbon dioxide capture and storage (BECCS) and afforestation are the only CDR methods under consideration because of limited comprehensive assessment of feasibility, cost, side effects, and environmental impacts of other CDR technologies. Terrestrial CDR techniques could involve local and regional risks, while maritime CDR techniques may involve significant risks to ocean ecosystems. ${ }^{13}$

\section{The Transport Sector}

Renewable energy sources are capable of supplying electricity, but some sources can supply thermal and mechanical energy as well as produce fuels that can satisfy multiple energy service needs. The global transport sector accounted for 27 percent of end-user energy use in 2010. Without implementation of aggressive and sustained mitigation policies, transport sector emissions could increase faster than other energy end-use sectors and could lead to more than a doubling of $\mathrm{CO}_{2}$ emissions by $2050 .{ }^{17,46,55}$

Electric, hydrogen, and some biofuel technologies could help reduce the carbon intensity of fuels. Commercially available liquid and gaseous biofuels already provide co-benefits together with mitigation options that can be increased by technology advances, particularly drop-in biofuels (biofuels that are completely interchangeable with conventional fuels) for aircraft. ${ }^{55}$ Energy efficiency measures through improved vehicle and engine designs have a large potential for emissions reductions, but the ultimate contribution of this sector to climate change mitigation will depend on the future electrification of transportation or on the use of RE to produce other energy carriers, e.g. hydrogen. ${ }^{56-58}$

\section{Human Ability to Understand Climate Change and Promote Mitigation Strategies}

Stabilizing greenhouse gas concentrations will require large-scale transformations in human societies, starting from energy production and saving, extending to land use, soil protection, and water management, ${ }^{17}$ but both citizens and decision makers often do not have sufficient knowledge about climate risks. This issue can and needs to be addressed through dissemination of more reliable and understandable information and data, and public education that results in a general literacy about the subject. Decision making is affected by knowledge and awareness, but motivation is driven by cultural differences in values and needs, which are equally or more important and, in turn, can lead to differences in beliefs about the existence and causes of climate change. ${ }^{59}$

This issue must be addressed first of all by a much more effective and diffused communication strategy by the scientific community, which needs to focus on the message, both in terms of content and audience. All people and particularly decision makers must become priority targets and must be reached by comprehensible, scientifically correct, relevant, and reliable information that could be 
effectively put to use immediately. Specialized academic and scholarly publications that reach only other scientists, and mainly environmentspecialized scientists, are no longer sufficient.

How the climate system is changing, why, in how much time, and the uncertainties must become common knowledge within and outside academia and shared by all disciplines because all contributions are strongly needed to face the crisis of climate change. A first-person awareness deployed across all disciplines can lead to better communication and more reliable knowledge. This poses one more challenge to the scientist: to promote and build day-by-day effective communication channels in all fields, urging involvement and coordination to start working togethereverywhere and now.

Only an extraordinary, coordinated and growing effort involving a strong and deep integration of different cultures, different knowledge bases, from humanities and arts to natural, applied, and social science, and different roles from decision makers to the whole society, can achieve results. Certainly this effort is necessary considering that the denial of climate change and of its causes is always alive and, possibly will continue to be so in the future. ${ }^{60,61}$

Two examples, related to two key issues of mitigation strategies, can help understand the fundamental need for an unprecedented integration of different approaches: water recycling and wind turbines. Both are related to the difficulty of gaining public acceptance for changes in lifestyles.

\section{Recycling, Reusing,...Refusing}

Fresh water is a limited resource, and safe drinking water will become more and more scarce in the future, especially at low latitudes. ${ }^{13}$ For this reason water recycling could become a mandatory approach to manage this precious resource.

One of the most advanced water recycling plants in the world is in San Diego, California, where recycled water was introduced as early as the 1990s. A local newspaper published an article about the plant, coining the phrase "toilet-to-tap." Thereafter recycled water became associated with the "yuck factor," effectively killing its support.

Binz et al. ${ }^{62}$ report that the current implementation of reuse schemes in California shows that acceptance of reuse technology must be understood as a complex socio-technical development process, and that the recent successes are the result of a 40year-long system-building process to legitimize potable reuse. In San Diego proven technology has been adopted to purify recycled water (membrane filtration, reverse osmosis, and advanced oxidation with ultraviolet light and hydrogen peroxide) and rigorous daily monitoring ensures no contaminants are present in the water; yet only indirect potable reuse is currently accepted and adopted; treated water is not sent straight to the tap (direct potable reuse) but it is sent to a reservoir where it is treated again before being piped to homes.

According to Rozin et al. ${ }^{63}$ rejection of recycled water is attributable to the way the concept is framed. Unwarranted fear of contamination and contagion also influence resistance to and disgust about consumption of recycled water. Therefore tap water is often rated as significantly more desirable than wastewater that has undergone substantially greater purification than water from the tap.
In their study of the relationship between information and sociodemographic factors in adopting recycled water, Hui and Cain ${ }^{64}$ sampled 1,500 adult Californians and found that using recycled water for drinking, bathing, and cooking were linked with resistance, independent of the level of education. Long-term societal legitimization of water reuse, particularly if the potable water supply is involved, is the main stumbling block, not the technical and economical aspects.

More cross-disciplinary efforts are needed in order to provide not only reliable and understandable information, but also to address rational, emotional, and experiential problems and to gain a better understanding of how precognitive affective reactions (e.g., the "yuck factor") influence responses to water reuse and its public acceptance. ${ }^{65}$

\section{The Aesthetics of New Landscapes}

The aesthetics of wind turbines as features of a new landscape are at the center of serious controversies. ${ }^{66}$ Their presence not only is often considered a danger for birds, a source of noise pollution, a source of severe disturbance due to the intermittent shadow projected by the rotating blades, but also as a visual intrusion on the preexisting landscape. This latter specific feature alone put contemporary wind turbines and their traditional counterparts (windmills) in oppositional positions in the public perception: traditional windmills are seen as an attractive feature while wind turbines as a curse.

On the other hand, according to the European Environment Agency, ${ }^{67}$ the potential of raw wind energy in Europe alone may be equivalent to almost 20 times its energy demand in 2020. This makes wind-turbine 
technology a choice that cannot be ignored; every effort to increase public acceptance of this technology deserves great attention. A proactive approach could be taken, not merely to simply increase public acceptance of renewable energy, but also to address the challenge of making a renewable energy plant beautiful and attractive if art and technology meet and explore new paths to a sustainable future, starting from a strong reciprocal interest and contamination. The following is an example of a totally different strategy to deal with the visual impact of wind turbines. Currently, manufacturers try to make wind turbines a part of the skyline, with gray towers that blend in with the sky. ${ }^{66}$ Instead of fulfilling the impossible mission of making wind turbines invisible, German artist Horst Glasker, ${ }^{68}$ in his AERO_Art project, ${ }^{69}$ dares to propose to make them "works of art for all to see" that "can appear as sculptural, vibrant objects in their own right."70

\section{Conclusion}

First, the international scientific community (see Supplementary Information) should make every effort to proactively gain attention and be trusted by all disciplines as well as by the general public, and work toward disseminating scientific information in a complete and comprehensible way. People in all disciplines must acquire an in-depth knowledge about what is happening to our climate and how environmental phenomena are studied and described, including all the limitations and uncertainties. All fields of knowledge and activity could make important contributions to dealing with climate and related environmental crises. The general public ought to be extensively involved in the discussion and evaluation of information about climate change and proposed strategies to face it, both on a global level and a local level (where the impact of such strategies is usually more apparent). It is time to put every effort into working across disciplines to advance knowledge, build competencies, and understand the roles played by various actors in the contributions they can make now and in the future, in unprecedented and unexpected ways. Just to save our home planet.

\section{Acknowledgments}

The author is grateful to Annalisa Romani (DISIA) director of the projects "Characterization of innovative antimicrobial and antioxidant products based on natural active ingredients for green agriculture uses" (produced by EVERGREENBIOS srl and EVERGRENN-LIFE UE 20142917) and "Innovative use of active substrate and phytoremediation technology in environmental impact of Lindane and hydrocarbons in soils and the evaluation of environmental, social and human health BES indexes" (produced by the Municipality of Ceccano, PIN SCRL and CHICO Cluster, PSR 2014-2020 GORegione Lazio), which contributed to Open Access Option funding.

\section{Supplementary Material}

Supplementary Information

\section{Author Disclosure Statement}

No competing financial interests exist.

\section{References}

1. United Nations (UN). http:// www.un.org/en/index.html (last accessed 12/13/2018).

2. World Meteorological Organization (WMO). https://public.wmo.int/ en (last accessed 12/13/2018).
3. United Nations Environment Programme (UNEP). http://www.unep .org/ (last accessed 12/13/2018).

4. Intergovernmental Panel on Climate Change (IPCC). http://www .ipcc.ch/organization/organization .shtml (last accessed 12/13/2018).

5. Intergovernmental Panel on Climate Change (IPCC). Preparing Reports. https://www.ipcc.ch/about/ preparingreports/ (last accessed 12/ 13/2018).

6. World Meteorological Organization (WMO). https://library.wmo.int/ opac/index.php?lvl=infopages\&lang= en_UK\&pagesid=1 (last accessed 12/ 13/2018).

7. United Nations Environment Programme (UNEP). UN EnvironmentResources. http://www.unep.org/ publications/ (last accessed 12/13/ 2018).

8. Intergovernmental Panel on Climate Change (IPCC). https://www .ipcc.ch/library/ (last accessed 06/ 28/2019).

9. World Meteorological Organization (WMO). Statement on the State of the Global Climate. https://public .wmo.int/en/our-mandate/climate/ wmo-statement-state-of-global-climate (last accessed 12/13/2018).

10. World Meteorological Organization (WMO). Statement on the State of the Global Climate in 2017. WMONo. 1212; 2018. https://library.wmo .int/opac/doc_num.php?explnum_id= 3414 (last accessed 12/13/2018).

11. Intergovernmental Panel on Climate Change (IPCC). Procedures. https://www.ipcc.ch/documentation/ procedures/ (last accessed 12/13/ 2018).

12. Intergovernmental Panel on Climate Change (IPCC). Fifth Assessment Report. https://www.ipcc.ch/ report/ar5/syr/ (last accessed 12/13/ 2018).

13. Intergovernmental Panel on Climate Change (IPCC). Climate Change 2014: Synthesis Report. Contribution 
of Working Groups I, II and III to the Fifth Assessment Report of the Intergovernmental Panel on Climate Change. IPCC, Geneva, 2014. https:// www.ipcc.ch/site/assets/uploads/2018/ 02/AR5_SYR_FINAL_SPM.pdf (last accessed 12/13/2018).

14. Intergovernmental Panel on Climate Change (IPCC). Climate Change 2013: The Physical Science Basis. Contribution of Working Group I to the Fifth Assessment Report of the Intergovernmental Panel on Climate Change. Cambridge University Press, Cambridge, England, and New York, 2013. https://www.ipcc.ch/site/assets/ uploads/2018/02/WG1AR5_all_final .pdf (last accessed 12/13/2018).

15. Intergovernmental Panel on Climate Change (IPCC). Climate Change 2014: Impacts, Adaptation, and Vulnerability. Part A: Global and Sectoral Aspects. Contribution of Working Group II to the Fifth Assessment Report of the Intergovernmental $\mathrm{Pa}$ nel on Climate Change. Cambridge University Press, Cambridge, England, and New York, 2014. https:// www.ipcc.ch/site/assets/uploads/2018/ 02/WGIIAR5-PartA_FINAL.pdf (last accessed 12/13/2018).

16. Intergovernmental Panel on Climate Change (IPCC). Climate Change 2014: Impacts, Adaptation, and Vulnerability. Part B: Regional Aspects. Contribution of Working Group II to the Fifth Assessment Report of the Intergovernmental Panel on Climate Change. Cambridge University Press, Cambridge, England, and New York, 2014. https://www .ipcc.ch/site/assets/uploads/2018/02/ WGIIAR5-PartB_FINAL.pdf (last accessed 12/13/2018).

17. Intergovernmental Panel on Climate Change (IPCC). Climate Change 2014: Mitigation of Climate Change. Contribution of Working Group III to the Fifth Assessment Report of the Intergovernmental Panel on Climate Change. Cambridge University Press,
Cambridge, England, and New York, 2014. https://www.ipcc.ch/site/assets/ uploads/2018/02/ipcc_wg3_ar5_full .pdf (last accessed 12/13/2018).

18. Cubasch U, Wuebbles D, Chen $\mathrm{D}$, et al. Introduction. In Stocker TF, Qin D, Plattner G-K, et al. (eds.), Climate Change 2013: The Physical Science Basis. Contribution of Working Group I to the Fifth Assessment Report of the Intergovernmental Panel on Climate Change. Cambridge University Press, Cambridge, England, and New York, 2013, pp 119-158.

19. Stocker TF, Qin D, Plattner GK, et al. Technical summary. In Stocker TF, Qin D, Plattner G-K, et al. (eds.), Climate Change 2013: The Physical Science Basis. Contribution of Working Group I to the Fifth Assessment Report of the Intergovernmental Panel on Climate Change. Cambridge University Press, Cambridge, England, and New York, 2013, pp 33-118. 20. World Meteorological Organization (WMO). Statement on the State of the Global Climate in 2016. WMONo. 1189; 2017. https://library.wmo .int/opac/doc_num.php?explnum_id= 3414 (last accessed 12/13/2018).

21. Butler JH, and Montzka SA. The NOAA Annual Greenhouse Gas Index (AGGI). U.S. Department of Commerce, National Oceanic and Atmospheric Administration, Earth System Research Laboratory, Global Monitoring Division, 2017. https:// www.esrl.noaa.gov/gmd/aggi/aggi.html (last accessed 12/13/2018).

22. Hartmann DL, Klein Tank AMG, Rusticucci M, et al. Observations: Atmosphere and surface. In Stocker TF, Qin D, Plattner G-K, et al. (eds.), Climate Change 2013: The Physical Science Basis. Contribution of Working Group I to the Fifth Assessment Report of the Intergovernmental Panel on Climate Change. Cambridge University Press, Cambridge, England, and New York, 2013, pp. 159-254.
23. Vaughan DG, Comiso JC, Allison I, et al. Observations: Cryosphere. In Stocker TF, Qin D, Plattner G-K, et al. (eds.), Climate Change 2013: The Physical Science Basis. Contribution of Working Group I to the Fifth Assessment Report of the Intergovernmental Panel on Climate Change. Cambridge University Press, Cambridge, England, and New York, 2013, pp. 317-382.

24. Thomson J, and Rogers WE. Swell and sea in the emerging Arctic Ocean. Geophys Res Lett 2014;41:3136-3140. http://onlinelibrary.wiley.com/doi/10 .1002/2014GL059983/pdf (last accessed 6/23/2019).

25. Hubbard BP, Sharp MJ, Willis IC, et al. Borehole water-level variations and the structure of the subglacial hydrological system of Haut Glacier d'Arolla, Valais, Switzerland. J Glaciol 1995; 41(139). https://www.cambridge .org/core/services/aop-cambridgecore/content/view/C95E873C4103D E67298D4DBD8CCA2455/S00221430 00034894a.pdf/borehole_waterlevel_ variations_and_the_structure_of_the_ subglacial_hydrological_system_ of_haut_glacier_darolla_valais_ switzerland.pdf (last accessed 12/13/ 2018).

26. Zwally HJ. Surface melt-induced acceleration of Greenland ice-sheet flow. Science 2002;297:218-222. http:// www.jstor.org/stable/pdf/3077049 .pdf (last accessed 12/13/2018).

27. Rignot E, and Kanagaratnam P. Changes in the velocity structure of the Greenland ice sheet. Science 2006;311. http://escholarship.org/uc/ item/7f48j474.pdf (last accessed 12/ 13/2018).

28. Shannon SR, Payne AJ, Bartholomew ID, et al. Enhanced basal lubrication and the contribution of the Greenland ice sheet to future sea-level rise. PNAS 2013;110 (35) 14156-14161. www.pnas.org/cgi/doi/10.1073/pnas.12 12647110 (last accessed 12/13/2018). 
29. Bhaumik AK, Gupta A, Gupta AK, et al. Gas hydrates occurrence, destabilization ands potential energy resources: A review based on faunal, geochemical and geophysical investigations with special reference to the Blake Ridge, NW Atlantic. J Palaeontol Soc India 2013;58. http:// palaeontologicalsociety.in/aug14/vol 58_1/5.pdf (last accessed 12/13/2018). 30. Walter KM, Anthony P, Grosse $\mathrm{G}$, et al. Geologic methane seeps along boundaries of Arctic permafrost thaw and melting glaciers. Nat Geosci 2012;5. https://www.research gate.net/profile/Katey_Walter_Anthony/ publication/233946553_Geologic_ methane_seeps_along_boundaries_ of_Arctic_permafrost_thaw_and_ melting_glaciers/links/00b7d535a e2c1bc381000000.pdf (last accessed 12/13/2018).

31. Walter KM, Zimov SA, Chanton JP, et al. Methane bubbling from Siberian thaw lakes as a positive feedback to climate warming. Nature 2006;443: 71-75. https://www.researchgate.net/ profile/S_Zimov/publication/683 2010_Methane_Bubbling_From_ Siberian_Thaw_Lakes_as_a_Positive_ Feedback_to_Climate_Warming/links/ 0f317533bc45c8971d000000.pdf (last accessed 12/13/2018).

32. Walter KM, Smith LC, and Chapin III FS. Methane bubbling from northern lakes: Present and future contributions to the global methane budget. Phil Trans R Soc A 2007;365. http://rsta.royalsocietypublishing.org/ content/365/1856/1657.full.pdf+html. (last accessed 6/25/2019).

33. Church JA, Clark PU, Cazenave A, et al. Sea level change. In Stocker TF, Qin D, Plattner G-K, et al. (eds.), Climate Change 2013: The Physical Science Basis. Contribution of Working Group I to the Fifth Assessment Report of the Intergovernmental Panel on Climate Change. Cambridge University Press, Cam- bridge, England, and New York, 2013, pp. 1137-1216.

34. Kopp RE, Hay CC, Little CM, et al. Geographic variability of sea-level change. Curr Clim Change Rep 2015. http://link.springer.com/article/10 .1007/s40641-015-0015-5 (last accessed 12/13/2018).

35. McGuire B. Hazardous responses of the solid Earth to a changing climate. In McGuire B, and Maslin M (eds.), Climate Forcing of Geological Hazards. The Royal Society and John Wiley \& Sons, $1^{\text {st }}$ ed., 2012, ch. 1. http://content.schweitzer-online.de/ static/catalog_manager/live/media_ files/representation/zd_std_orig zd_schw_orig/002/061/950/9780 470658659_content_pdf_1.pdf (last accessed 12/13/2018). DOI: 10.1002/ 9781118482698.ch1

36. Sweet WV, Kopp RE, Weaver $\mathrm{CP}$, et al. Global and Regional Sea Level Rise Scenarios for the United States. NOAA Technical Report NOS CO-OPS 083, 2017. ftp://ftp.library .noaa.gov/noaa_documents.lib/NOS/ COOPS/TR/TR_NOS_COOPS_083 .pdf (last accessed 12/13/2018).

37. Boucher O, Randall D, Artaxo P, et al. Clouds and aerosols. In Stocker TF, Qin D, Plattner G-K, et al. (eds.), Climate Change 2013: The Physical Science Basis. Contribution of Working Group I to the Fifth Assessment Report of the Intergovernmental Panel on Climate Change. Cambridge University Press, Cambridge, England, and New York, 2013, pp. 571-658.

38. Trenberth KE, Fasullo JT, and Shepherd TG. Attribution of climate extreme events. Nat Clim Chang 2015;5:8. http://dx.doi.org/10.1038/ nclimate2657 (last accessed 12/13/ 2018).

39. Ciais P, Sabine C, Bala G, et al. Carbon and other biogeochemical cycles. In Stocker TF, Qin D, Plattner $\mathrm{G}-\mathrm{K}$, et al. (eds.), Climate Change 2013: The Physical Science Basis.
Contribution of Working Group I to the Fifth Assessment Report of the Intergovernmental Panel on Climate Change. Cambridge University Press, Cambridge, England, and New York, 2013, pp. 465-570.

40. Rhein M, Rintoul SR, Aoki S, et al. Observations: Ocean. In Stocker TF, Qin D, Plattner G-K, et al. (eds.), Climate Change 2013: The Physical Science Basis. Contribution of Working Group I to the Fifth Assessment Report of the Intergovernmental Panel on Climate Change. Cambridge University Press, Cambridge, England, and New York, 2013, pp. 255-316.

41. Raven J, Caldeira K, Elderfield $\mathrm{H}$, et al. Ocean Acidification Due to Increasing Atmospheric Carbon Dioxide. The Royal Society, London, 2005. http://royalsociety.org/uploaded Files/Royal_Society_Content/policy/ publications/2005/9634.pdf (last accessed 12/13/2018).

42. Kleypas JA, Feely RA, Fabry VJ, et al. Impacts of Ocean Acidification on Coral Reefs and Other Marine Calcifiers: A Guide for Future Research. NSF, NOAA, and the U.S. Geological Survey Report, 2006. https://www.researchgate.net/profile/ Joan_Kleypas/publication/248700866_ Impacts_of_Ocean_Acidification_on_ Coral_Reefs_and_Other_Marine_ Calcifiers_A_Guide_for_Future_ Research__St_Petersburg_Report/ links/54b577eb0cf2318f0f998b54.pdf (last accessed 12/13/2018).

43. Bendtsen J, and Hansen JLS. Effects of global warming on hypoxia in the Baltic Sea-North Sea transition zone. Ecol Modell 2013;264:1726. http://www.sciencedirect.com/ science/article/pii/S0304380012002 906/pdfft? $\mathrm{md} 5=85458$ ac655136432 4605b7c39bbe3909\&pid=1-s2.0-S0 304380012002906-main.pdf (last accessed 12/13/2018).

44. United Nations (UN). Framework Convention on Climate Change 
(FCCC). Adoption of the Paris Agreement, 2015. FCCC/CP/2015/L.9/Rev.1 http://unfccc.int/resource/docs/2015/ cop21/eng/109r01.pdf (last accessed 12/13/2018).

45. Collins M, Knutti R, Arblaster J, et al. Long-term climate change: Projections, commitments and irreversibility. In Stocker TF, Qin D, Plattner G-K, et al. (eds.), Climate Change 2013: The Physical Science Basis. Contribution of Working Group I to the Fifth Assessment Report of the Intergovernmental Panel on Climate Change Cambridge University Press, Cambridge, England, and New York, 2013, pp. 1029-1136.

46. Myhre G, Shindell D, Bréon F-M, et al. Anthropogenic and natural radiative forcing. In Stocker TF, Qin D, Plattner G-K, et al. (eds.), Climate Change 2013: The Physical Science Basis. Contribution of Working Group I to the Fifth Assessment Report of the Intergovernmental Panel on Climate Change. Cambridge University Press, Cambridge, England, and New York, 2013, pp 659-740.

47. Kirtman B, Power SB, Adedoyin JA, et al. Near-term climate change: Projections and predictability. In Stocker TF, Qin D, Plattner G-K, et al. (eds.), Climate Change 2013: The Physical Science Basis. Contribution of Working Group I to the Fifth Assessment Report of the Intergovernmental Panel on Climate Change. Cambridge University Press, Cambridge, England, and New York, 2013, pp. 953-1028.

48. Fischedick M, Schaeffer R, Adedoyin A, et al. Mitigation potential and costs. In Edenhofer O, PichsMadruga R, Sokona Y, et al. (eds.], IPCC Special Report on Renewable Energy Sources and Climate Change Mitigation. Cambridge University Press, Cambridge, England, and New York, 2011, pp. 791-864.

49. Sovacool BK. Valuing the greenhouse gas emissions from nuclear power: A critical survey. Energy Policy 2008; 36:2940-2953. https:// www.nirs.org/climate/background/ sovacool_nuclear_ghg.pdf (last accessed 12/13/2018).

50. Vujic J, Bergmann RM, Skoda R, et al. Small modular reactors: Simpler, safer, cheaper? Energy 2012;45(1):288295. https://www.sciencedirect.com/ science/article/pii/S03605442120009 3X (last accessed 7/1/2019).

51. Magwood WD IV, and Paillere H. Looking ahead at reactor development. Progress Nucl Energy 2018; 102:58-67. https://doi.org/10.1016/ j.pnucene.2017.07.001 (last accessed 12/13/2018).

52. Wurden GA, Hsu SC, Intrator $\mathrm{TP}$, et al. Magneto-inertial fusion. Fusion Energy 2016;35(1):69-77. https://link.springer.com/article/10. 1007/s10894-015-0038-x (last accessed 06/28/2019).

53. Eldardiry $\mathrm{H}$, and Habib E. Carbon capture and sequestration in power generation: Review of impacts and opportunities for water sustainability. Energy Sustain Soc 2018;8(6):1-51. https://energsustainsoc.biomedcentral .com/articles/10.1186/s13705-018-01463 (last accessed 06/28/2019).

54. Leung DC, Caramanna GM, and Maroto-Valer M. An overview of current status of carbon dioxide capture and storage technologies. Renew Sustain Energy Rev 2014;39:426-443. https://doi.org/10.1016/j.rser.2014.07 .093 (last accessed 12/13/2018).

55. Sims R, Schaeffer R, Creutzig F, et al. Transport. In Edenhofer $\mathrm{O}$, Pichs-Madruga R, Sokona Y, et al. (eds.), Climate Change 2014: Mitigation of Climate Change. Contribution of Working Group III to the Fifth Assessment Report of the Intergovernmental Panel on Climate Change. Cambridge University Press, Cambridge, England, and New York, 2014, pp 599-670.

56. Delucchi MA, and Jacobson MZ. Providing all global energy with wind, water, and solar power, Part II: Reliability, system and transmission costs, and policies. Energy Policy 2011. https://web.stanford.edu/ group/efmh/jacobson/Articles/I/DJ EnPolicyPt2.pdf (last accessed 12/ 13/2018).

57. Jacobson MZ, and Delucchi MA. Providing all global energy with wind, water, and solar power, Part I: Technologies, energy resources, quantities and areas of infrastructure and materials. Energy Policy 2011;39:11541169. https://web.stanford.edu/ group/efmh/jacobson/Articles/I/JDEn PolicyPt1.pdf (last accessed 12/13/ 2018).

58. Steinke F, Wolfrum $P$, and Hoffmann C. Grid vs. storage in a $100 \%$ renewable Europe. Renewable Energy 2013;50:826-832. http://dx.doi .org/10.1016/j.renene.2012.07.044 (last accessed 12/13/2018).

59. Leiserowitz, A. Climate change risk perception and policy preferences: The role of affect, imagery, and values. Clim Change 2006; 77:45-72. https://doi.org/10.1007/ s10584-006-9059-9 (last accessed 12/13/2018).

60. Myers TC. Understanding climate change as an existential threat: Confronting climate denial as a challenge to climate ethics. De Ethica. J Philosl Theol Appl Ethics 2014; 1(1):53-70. http://www.de-ethica.com/ archive/articles/v1/i1/a06/de_ethica_ 14vlila06.pdf (last accessed 12/13/ 2018).

61. Wyatt $\mathrm{T}$, and Brisman A. The role of denial in the 'Theft of Nature': Comparing biopiracy and climate change. Crit Crim 2017;25:325-341. https://link.springer.com/content/pdf/ 10.1007\%2Fs10612-016-9344-5.pdf (last accessed 12/13/2018). DOI 10. 1007/s10612-016-9344-5.

62. Binz C, Harris-Lovett S, Kiparsky $\mathrm{M}$, et al. The thorny road to technology legitimization-Institutional work for potable water reuse in California. 
Technol Forecast Soc Change 2016; 103:249-263. https://doi.org/10.1016/j .techfore.2015.10.005 (last accessed 12/13/2018).

63. Rozin P, Haddad B, Nemeroff C, et al. Psychological aspects of the rejection of recycled water: Contamination, purification and disgust. Judgm Decis Mak 2015;10(1):50-63. https://scholarsbank.uoregon.edu/ xmlui/handle/1794/19440 (last accessed 12/13/2018).

64. Hui I, and Cain BE. Overcoming psychological resistance toward using recycled water in California. Water and Environ J 2017;32:17-25. https:// onlinelibrary.wiley.com/doi/full/10 $.1111 /$ wej.12285 (last accessed 12/13/ 2018).

65. Smith HM, Brouwer S, Jeffrey $\mathrm{P}$, et al. Public responses to water reuse-Understanding the evidence. J Environ Manage 2014; 207. https://doi.org/10.1016/j.jenvman .2017.11.021 (last accessed 12/13/ 2018).

66. Good J. The aesthetics of wind energy. Human Ecology Review 2006;13(1):76-89. http://trangwww .humanecologyreview.org/pastissues/ her 131/good.pdf (last accessed 12/13/ 2018).

67. European Environment Agency. Europe's onshore and offshore wind energy potential. An assessment of environmental and economic constraints. EEA Technical report No 6/2009. https://www.eea .europa.eu/publications/europesonshore-and-offshore-wind-energypotential/at_download/file (last accessed 12/13/2018).

68. Gläsker H. Horst Gläsker. On the Rhythm of Images. http://www
.horst-glaesker.de/index_EN.html (last accessed 6/23/2019).

69. Gläsker H. AERO_Art. Future Project. http://www.aero-art.com/ index.html (last accessed 6/23/ 2019).

70. Gläsker H. Symbols of a Creative Economy. AERO_art project. http:// www.aero-art.com/e_page2.html (last accessed 6/23/2019).

Address correspondence to:

Stefano Alessandri

University of Florence

Department of Statistics, Computer

Science, and Applications

Viale Morgagni, 59 - 50134

Florence

Italy

E-mail: stefano.alessandri@unifi.it 